Check for updates

Cite this: RSC Adv., 2019, 9, 17905

\title{
New protic ionic liquids for fungi and bacteria removal from paper heritage artefacts $\dagger$
}

\author{
Nataša Dimitrić, ${ }^{a}$ Nemanja Spremo, ${ }^{a}$ Milan Vraneš, (DD a Sanja Belić, ${ }^{a}$ Maja Karaman, ${ }^{a}$ \\ Strahinja Kovačević, ${ }^{\mathrm{b}}$ Milica Karadžić, ${ }^{\mathrm{b}}$ Sanja Podunavac-Kuzmanović, ${ }^{\text {b }}$ \\ Daniela Korolija-Crkvenjakov ${ }^{c}$ and Slobodan Gadžurić (DD *a
}

In this work, new protic ionic liquids (PILS) with 1-ammonium-2-propanol cation and nine different anions: formate (For), acetate (AC), lactate (Lac), trifluoroacetate (TFA), chloroacetate (CIA), trichloroacetate (TCIA), 3-chloropropionate (3-CIP), 4-chlorobutyrate (4-CIB) and mandelate (Man) were prepared in order to study their antimicrobial activity and possible application for fungi and bacteria removal from deteriorated paper heritage. Ten filamentous fungal strains isolated from specific pigmented area of the damaged books: Trichoderma sp., Cladosporium sp., Penicillium sp. ${ }^{(1-3)}$, Penicillium citrinum, Aspergillus sp. ${ }^{(1,2)}$, Aspergillus flavus, Fusarium graminearum, eight Gram positive and Gram negative ATCC bacterial strains:

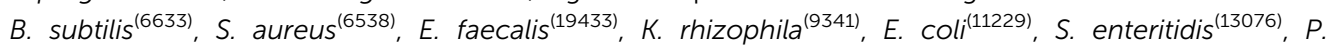
mirabilis ${ }^{(12453)}, P$. aeruginosa ${ }^{(15692)}$ and two yeast Candida strains: Candida albicans ${ }^{(\text {ATCC } 10231)}$ and Candida albicans ${ }^{(\mathrm{L})}$ were used in this study. The results indicated that antimicrobial activity of selected ionic liquids is significantly affected by the size and specific functional groups in the anion structure. These facts opened the possibility for molecular design of new ionic liquids with strong inhibition properties against the specific bacterial, mould and yeast strains. The significant antimicrobial properties observed in this research suggest that studied PILs may have potential applications in the paper art and artefact cleaning and conservation replacing thus, conventional solvents and organic substances that are toxic for humans and environment.

Received 25th April 2019 Accepted 28th May 2019 DOI: $10.1039 /$ c9ra03067k rsc.li/rsc-advances

\section{Introduction}

Paper is the most common substrate for recording information, and if appropriately manufactured, can be very resistant to ageing. ${ }^{1}$ As an object of cultural heritage it can be affected by diverse microbial communities, especially heterotrophic organisms such as fungi and bacteria. Their metabolites deteriorate the substrates on which they grow resulting in chemical and physical changes of the material bulk and surface leading to structural weakening. ${ }^{2}$ Some new advanced materials for paper/cellulosic materials treatment have been recently developed..$^{3-5}$ However, large number of documents, books, manuscripts and paper artefacts are in danger of imminent destruction and are becoming more fragile and unusable during the time. ${ }^{6,7}$ The rate of deterioration depends on internal

${ }^{a}$ Faculty of Science, University of Novi Sad, Trg Dositeja Obradovića 3, 21000 Novi Sad, Serbia. E-mail: slobodan.gadzuric@dh.uns.ac.rs; Fax: +381 21454 065; Tel: +381 21 4852744

${ }^{b}$ Faculty of Technology, University of Novi Sad, Bulevar Cara Lazara 1, 21000 Novi Sad, Serbia

${ }^{c}$ Academy of Art, University of Novi Sad, Đure Jakšića 7, 21000 Novi Sad, Serbia

$\dagger$ Electronic supplementary information (ESI) available: Fig. S1-S9 FTIR spectra of studied PILs; Fig. S10-S13 antifungal activity of PILs; Fig. S14-S23 antifungal activity of each microbial strain. See DOI: 10.1039/c9ra03067k factors, such as the nature of used materials, the production process, the $\mathrm{pH}$, and in the same time is controlled by external factors such as the climatic conditions, the pollution level and the biological activity. ${ }^{8-10}$ Biodeterioration, process of decay of culturally, historically and artistically significant object, including paper, induces by microorganisms, starts as soon as microbial spores land on surface where molecular water is present. Making a strategy towards prevention, mitigation of biodeterioration and removal of microorganisms, especially fungi begins with the understanding of the materials' fabric, assessment of causes behind the biodeterioration, and the context in which it occurs. ${ }^{2}$ For over 60 years, thymol (2isopropyl-5-methylphenol) has been used as a fungicide in paper conservation. It is easily absorbed by the human organism through breathing or skin contact and is considered to be of medium toxicity. It can be applied to paper either as an alcoholic solution by spraying, or more often as a vapour produced by sublimation in exposure chambers (fumigation). ${ }^{\mathbf{1 1}}$ In addition, it was showed that thymol is absorbed by paper and photoxidized, causing intense paper yellowing and also degradation of the paper support, water colour binder, and iron gall ink after thymol fumigation. ${ }^{12}$ The development of less harmful cleaning methods and applied solvents, both for health and the working environment is one of the major concerns for 
conservators and restorers. ${ }^{13}$ Therefore, the possibility of replacing such volatile and toxic organic solvents by green alternatives could contribute to safer procedures.

Ionic liquids are novel solvents of rising interest as greener alternatives to traditional volatile organic compounds aimed to facilitate so-called sustainable chemistry. ${ }^{\mathbf{1 4}}$ They are defined as organic salts consisting only of ions with a melting point below $100{ }^{\circ} \mathrm{C} .{ }^{15}$ Due to their unusual physical properties, recyclability and biodegradability, ionic liquids have attracted large interest of both industry and academia. ${ }^{\mathbf{1 4}}$ Also, there are several attempts to use ILs for paper conservation. ${ }^{\mathbf{1 6 - 1 8}}$ For example, their low volatility reduces the risks to health and the environment, their high viscosity may inhibit the penetration into the paper layers, and their adjustable miscibility with water or less toxic solvents allows their removal with safer solvents. Also, the antimicrobial activity of ionic liquids has quickly attracted the attention of researchers, since the fungal and bacterial deterioration is one of the main causes of the paper artefacts degradation process. The number of combinations of the ions that form ILs is estimated to $10^{18}$, so they have a significant potential to be tailored to the desired application, and new possible applications of ILs are discovered continuously. ${ }^{19-21}$

Based on their chemical behaviour, ILs can be divided into two groups: aprotic (AILs) and protic (PILs) ionic liquids. The aprotic group can be considered as "classic" ILs, while the representatives of the protic group are in the recent development. ${ }^{22}$ Thus, in this paper, nine new protic ionic liquids containing the same cation (1-ammonium-2-propanol) and different anions were synthesised, and their antimicrobial activity investigated both experimentally and using two chemometric techniques to discuss the possible application in restoration and conservation of the cultural heritage against isolated fungi and bacteria from damaged paper artworks. This amino alcohol is selected due to neglected toxicity, since toxicity effects to humans have not been reported. Low production costs, simple synthesis, miscibility with both polar and nonpolar solvents and also stability at normal conditions suggest great potential applications in various industries such as production of washing and cleaning materials or pharmaceuticals.

\section{Materials and methods}

All chemical for PILs synthesis were used as purchased from the manufacturer, without further purification: 1-amino-2-propanol (Merck, mass fraction purity $\omega=95 \%$ ), formic acid (Sigma Aldrich, $\omega=98 \%$ ), acetic acid (Centrohem, $\omega=99,8 \%$ ), lactic acid (Sigma Aldrich $\omega=98 \%$ ), trifluoroacetic acid (Sigma Aldrich, $\omega=98 \%$ ), chloroacetic acid (Sigma Aldrich, $\omega=99 \%$ ), trichloroacetic acid (Merck, $\omega=99,5 \%$ ), 3-chloropropanoic acid (Sigma Aldrich, $\omega=98 \%$ ), 4-chlorobutyric acid (Sigma Aldrich, $\omega=99 \%$ ) and mandelic acid (Centrohem, $\omega=98 \%$ ). Nine different protic ionic liquids were synthesized according to the synthetic path presented in Fig. 1.

In a typical preparation procedure of studied nine PILs, equal molar amount of anion was added dropwise to a 1-amino2-propanol and cooled in an ice-bath. After addition of the corresponding acid, the reaction mixture was stirred at room

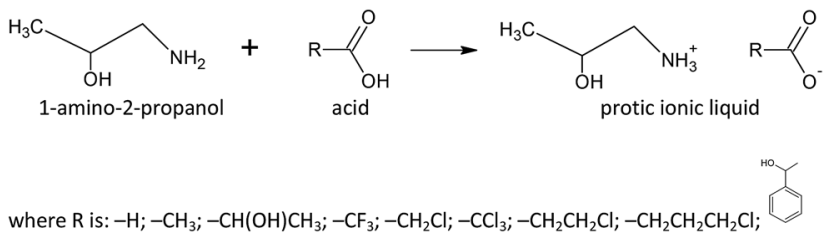

Fig. 1 The synthetic path for investigated protic ionic liquids.

temperature for 15 minutes. The obtained ionic liquid was dried under vacuum for the next 30 minutes to 3 hours to remove any traces of water. The obtained liquid products were kept under vacuum desiccator with $\mathrm{P}_{2} \mathrm{O}_{5}$ for the next $24 \mathrm{~h}$. After drying, the water content in the PILs was determined by the Karl Fisher titration (using Metrohm 831 Karl Fischer coulometer). The water content was found to be less than $100 \mathrm{ppm}$ in all prepared PILs.

\section{Vibrational spectra}

In order to determine the structure and the purity of obtained PILs, an infrared spectra were recorded on neat samples from (4000 to 650 ) $\mathrm{cm}^{-1}$ using a Thermo-Nicolet Nexus 670 spectrometer fitted with a Universal ATR Sampling Accessory. A single drop of synthesised protic ionic liquid was placed on top of the germanium crystal, and for each sample, a background experiment was performed under the same conditions. The Omnic 6.2 software was used for the data acquisition and spectral analysis. All the recorded spectra together with their assignation are given in the ESI (Fig. S1-S9†).

\section{Thermogravimetric analysis}

The thermal stability of the obtained PILs is investigated using thermogravimetric analysis (TGA). Thermogravimetric analysis was performed applying simultaneous TGA/DSC thermal analyser SDT Q600 (TA Instruments, USA). The sample $(\approx 2.5 \mathrm{mg}$ ) was placed in an open platinum pan. The measurements were carried out in a nitrogen atmosphere (flow rate $50 \mathrm{~cm}^{3} \mathrm{~min}^{-1}$ ) up to $600{ }^{\circ} \mathrm{C}$. The heating rate was set at $10{ }^{\circ} \mathrm{C} \mathrm{min}^{-1}$. Calibration curves were measured for each sample. The degradation temperatures of prepared PILs are present in Table 1.

\section{Antimicrobial assays}

Ten filamentous fungal strains, Trichoderma sp., Cladosporium sp., Penicillium sp. ${ }^{(1-3)}$ and Aspergillus sp. ${ }^{(1,2)}$, were isolated

Table 1 TG analysis of prepared PILs

\begin{tabular}{lc}
\hline Name & $\left(T_{\text {onset }} \pm 0.5\right)^{\circ} \mathrm{C}$ \\
\hline For & 144.0 \\
Ac & 117.0 \\
Lac & 67.3 \\
TFA & 189.5 \\
ClA & 177.8 \\
TClA & 114.7 \\
3-ClP & 86.2 \\
4-ClB & 58.7 \\
Man & 117.0
\end{tabular}


from specific pigmented area of the damaged books from the Matica Srpska Library (Novi Sad, Serbia) and three fungal strains, Aspergillus flavus $^{\mathrm{FCD} 00007}$, Fusarium graminearum ${ }^{\mathrm{FCD} 0016}$, Penicillium citrinum $^{\mathrm{FCD} 00033}$, were obtained from mycological culture collection of the Faculty of Sciences, Department of Biology and Ecology (University of Novi Sad, Serbia). Cultures were grown on Malt agar (Torlak, Serbia), which promoted fast growth and sporulation within 7 days at $27^{\circ} \mathrm{C}$. After incubation, a sample of the cultivated fungi was taken and suspended in sterile distilled water. Suspension of Trichoderma sp., Cladosporium sp., Penicillium sp. ${ }^{(1-3)}$, P. citrinum, Aspergillus sp. ${ }^{(1,2)}, A$. flavus and $F$. graminearum was adjusted at the density of $1.5 \times$ $10^{7}$ cells per $\mathrm{ml}(\mathrm{c} / \mathrm{ml})$. Bürker Türk chamber (hemocytometer) and a microscope were used to obtain the adequate inoculum turbidity and the desired density. The number of spores in the chamber was determined by direct counting using a microscope (Olympus, BX51, Japan) in the specific chamber cubes. The number of spores in a chamber is used to calculate the concentration or spore density in a suspension, using the following equation:

Mixture cell concentration $=$

$$
\frac{\text { number of counted cells }}{\text { number of chambers } \times \text { chamber volume }} \times 1000
$$

Eight standard ATCC bacterial strains, B. subtilis ${ }^{(6633)}, S$.

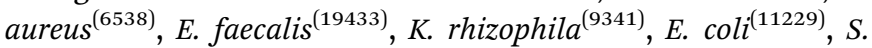
enteritidis $^{(13076)}$, P. mirabilis ${ }^{(12453)}$, P. $^{(10 r u g i n o s} a^{(15692)}$ and two Candida strains, C. albicans ${ }^{(\mathrm{ATCC} 10231)}$ and C. albicans $^{(\mathrm{L})}$, were obtained from the culture collection of the Faculty of Sciences, Department of Biology and Ecology (University of Novi Sad, Serbia). All bacterial strains were grown on Müeller-Hinton agar (Torlak, Serbia) at $26^{\circ} \mathrm{C}$ for $24 \mathrm{~h}$, while two Candida strains were grown on Malt agar at $37^{\circ} \mathrm{C}$ for $48 \mathrm{~h}$. Inocula for the assays were prepared by diluting scraped cell mass into $\omega=0.85 \% \mathrm{NaCl}$ solution, adjusted to a 0.5 McFarland standard (equivalent to 1 $\times 10^{8} \mathrm{CFU} \mathrm{ml}{ }^{-1}$ ). Turbidity was confirmed by a photoelectric photometer (Colorimeter MA 9504th Metrix).

The antifungal and antibacterial activity of studied PILs were determined in vitro by microdilution method in 96 well microtiter plates (Spektar, Serbia), to determine the minimal inhibitory, fungicide and bactericide concentrations (MIC, MFC and MBC) following the CLSI procedure ${ }^{23}$ and Spremo et al. ${ }^{24}$ Sterile polypropylene microtiter plates were used for this purpose. The total volume of a well was $101 \mu \mathrm{l}$. The amount of $50 \mu \mathrm{l}$ Malt broth (Torlak, Serbia) for fungi and Candida strains and Müeller-Hinton broth (Torlak, Serbia) for bacterial strains were applied into each well and $1 \mu \mathrm{l}$ of fungal spore/Candida/bacterial suspension in 9 double diluted solutions $(100 \%, 50 \%, 25 \%$, $12.5 \%, 6.25 \%, 3.125 \%, 1.56 \%, 0.78 \%$ and $0.39 \%)$. The protic ionic liquids were dissolved in sterile deionised water in the concentration range from (150 to 0.59$) \mathrm{mg} \mathrm{ml}^{-1}$. Each test plate included growth control and sterility PILs control.

Microtiter plates were incubated for $72 \mathrm{~h}$ at $27^{\circ} \mathrm{C}$ (fungi strains) $/ 48 \mathrm{~h}$ at $37^{\circ} \mathrm{C}\left(\right.$ Candida $\left.^{(\mathrm{ATCC} 10231)}\right) / 48 \mathrm{~h}$ at $26^{\circ} \mathrm{C}$ (Candi$\left.d a^{(\mathrm{L})}\right) / 24 \mathrm{~h}$ at $26{ }^{\circ} \mathrm{C}$ (bacterial strains), and the results were

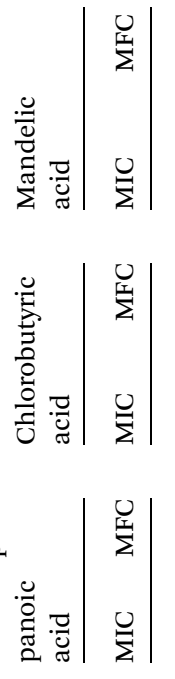

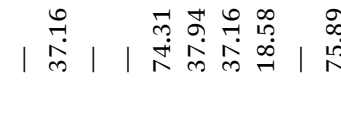

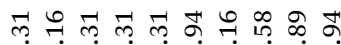

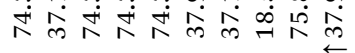

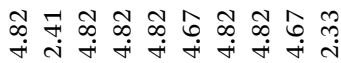

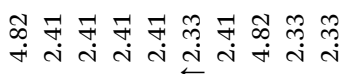

요요



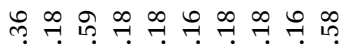

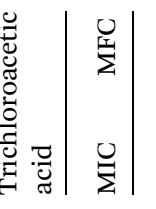

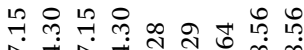

|

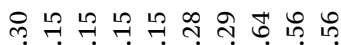

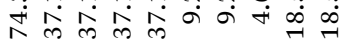

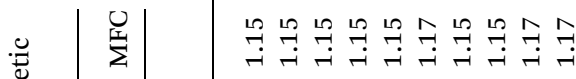

䢘

尊罚|

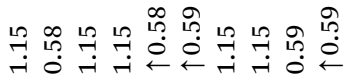

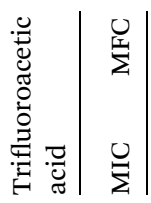

$\infty$

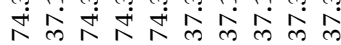

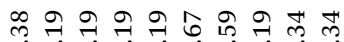

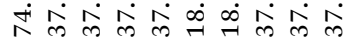

ถิ $\stackrel{\infty}{\rightarrow} \stackrel{\infty}{\rightarrow} \stackrel{\infty}{\sim} \sigma \sigma \sigma a \stackrel{\infty}{\sim}$

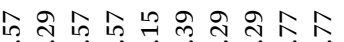

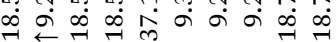

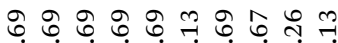

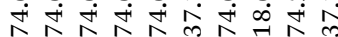

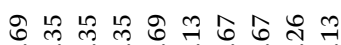

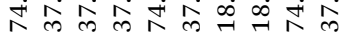

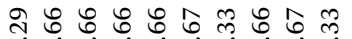
रें मं अं

ণิ 唡 +r 
obtained visually. A redox indicator of 2,3,5-triphenyltetrazolium chloride (TTC) was used to identify metabolically active bacterial cells. The first concentration of ionic liquid without visible growth was taken as minimal inhibitory concentration (MIC), while minimum fungicide/bactericide concentration (MFC/MBC) was determined after reading the MIC values, by transferring the whole volume of a well into Petri Malt agar or Müeller-Hinton agar plates. After incubation for $72 \mathrm{~h}$ at $27^{\circ} \mathrm{C}$ (fungal strains), $48 \mathrm{~h}$ at $37^{\circ} \mathrm{C}\left(\right.$ Candida $\left.^{(\mathrm{ATCC} 10231)}\right), 48 \mathrm{~h}$ at $26^{\circ} \mathrm{C}\left(\right.$ Candida $\left.^{(\mathrm{L})}\right)$ and $24 \mathrm{~h}$ at $26^{\circ} \mathrm{C}$ (bacterial strains), the results previously monitored by counting colonies were obtained.

\section{Chemometric analysis}

Hierarchical Cluster Analysis (HCA) has become widely used clustering method in chemometrics. ${ }^{25,26}$ It is well-known that HCA is based on the division of the analysed objects (samples, molecules, models) in that way, so the most similar objects (considering the space of the analysed variables) are placed in the same cluster. ${ }^{27}$ A graphical representation known as a dendrogram is shaped like a tree where the peripheral branches represent objects. Usually, there are two main clusters with certain number of sub-clusters. However, the dendrogram can show the presence of outliers, separating them from the other objects and/or clusters. In the present study, the joining (tree) clustering was applied by using Statistica $10{ }^{28}$ Ward's method was used as an amalgamation (linkage) rule with the Euclidean distances as a distance measure.

Sum of Ranking Differences (SRD) method is a simple and relatively new procedure for the reliable comparison of samples, models, objects or techniques. ${ }^{29}$ The detailed description of the SRD methodology can be found elsewhere. ${ }^{29-32}$ In the present study, the input matrix for SRD analysis is formed so the PILs to be ranked are placed into columns, while the antifungal activity data were organised in the rows. The set of reference values (reference ranking set or so-called golden standard) contained the minimum and average MIC values of the determined antifungal activity. ${ }^{30}$ The calculated SRD values, assigned to every ranked PILs, show their proximity to the reference ranking: the smaller SRD value, the better. ${ }^{31}$ SRD results can be validated by comparison of ranks by random numbers (CRRN) or crossvalidation approach. ${ }^{32}$

\section{Results and discussion}

The results obtained by the microdilution method are presented in Table 2 and Fig. S10 in ESI $\uparrow$ through a parallel review of MICs and MFCs of all fungal strains: Trichoderma sp., Cladosporium sp., Penicillium sp. ${ }^{(1-3)}$, P. citrinum, Aspergillus sp. ${ }^{(1,2)}$, A. flavus, F. graminearum, and two Candida strains: C. albicans $^{(\mathrm{ATCC}}{ }^{10231)}$ and C. albicans $^{(\mathrm{L})}$ (Table 3, Fig. S11 in ESI $†$ ), while parallel review of MICs and MBCs of four Gram-positive $(\mathrm{Gr}+)$ bacterial strains: B. subtilis ${ }^{(6633)}$, S. aureus $^{(6538)}$, E. faecalis $^{(19433)}, K$. rhizophila ${ }^{(9341)}$ and four Gram-negative $(\mathrm{Gr}-)$ bacterial strains: E. coli ${ }^{(11229)}$, S. enteritidis ${ }^{(13076)}$, P. mirabilis $^{(12453)}, P$. aeruginosa $^{(15692)}$ are presented in Table 4 and Fig. S12 and S13 as the ESI. $\dagger$ For the clearance, in Fig. S14-S23

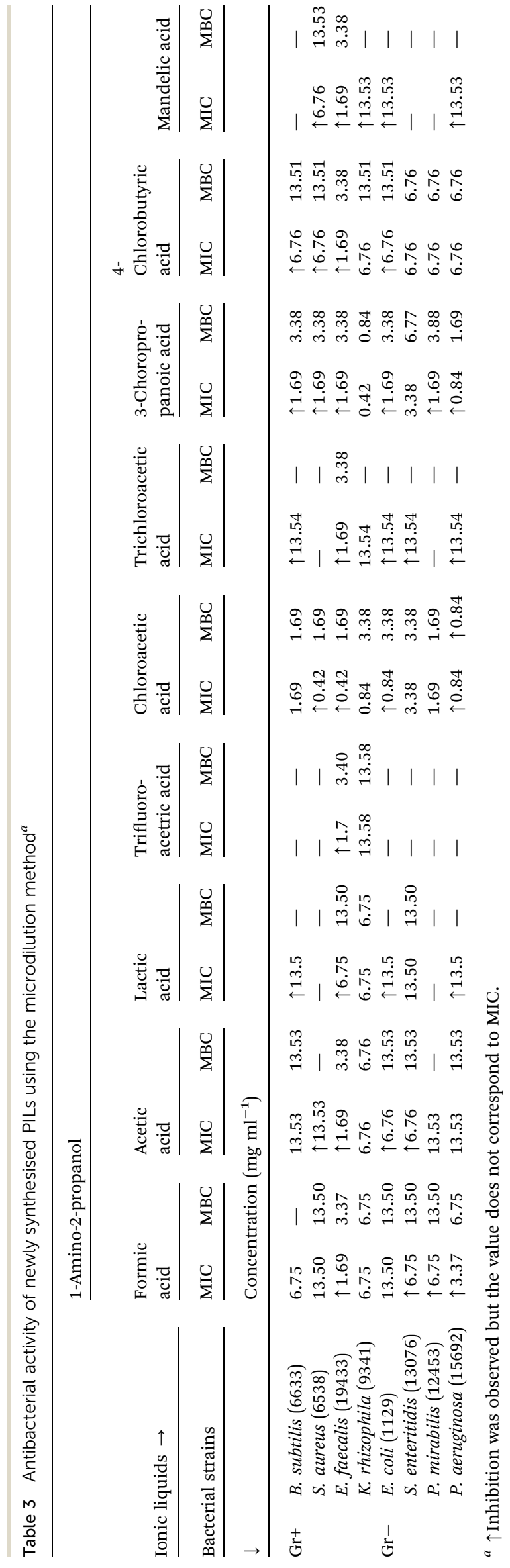




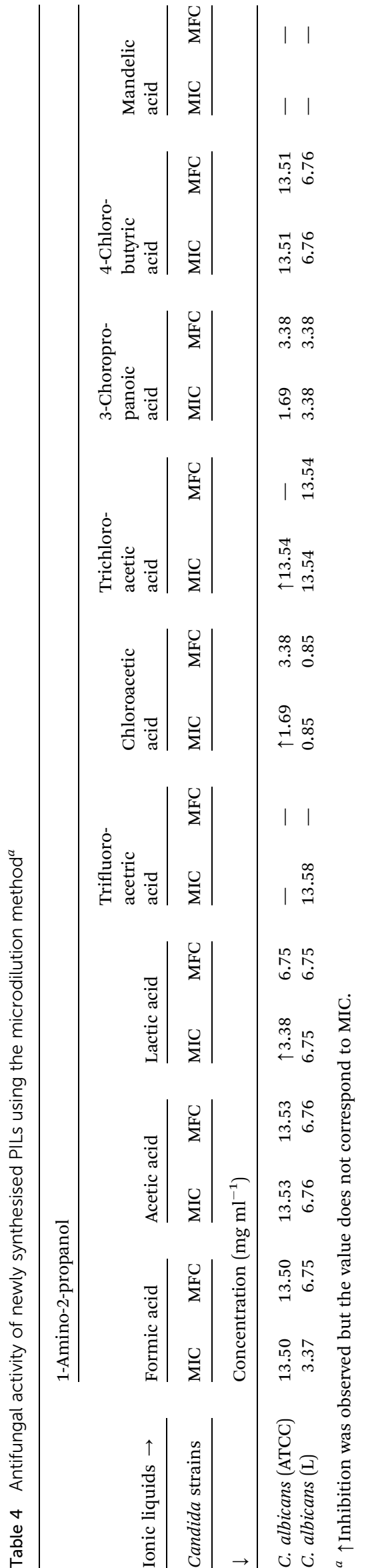

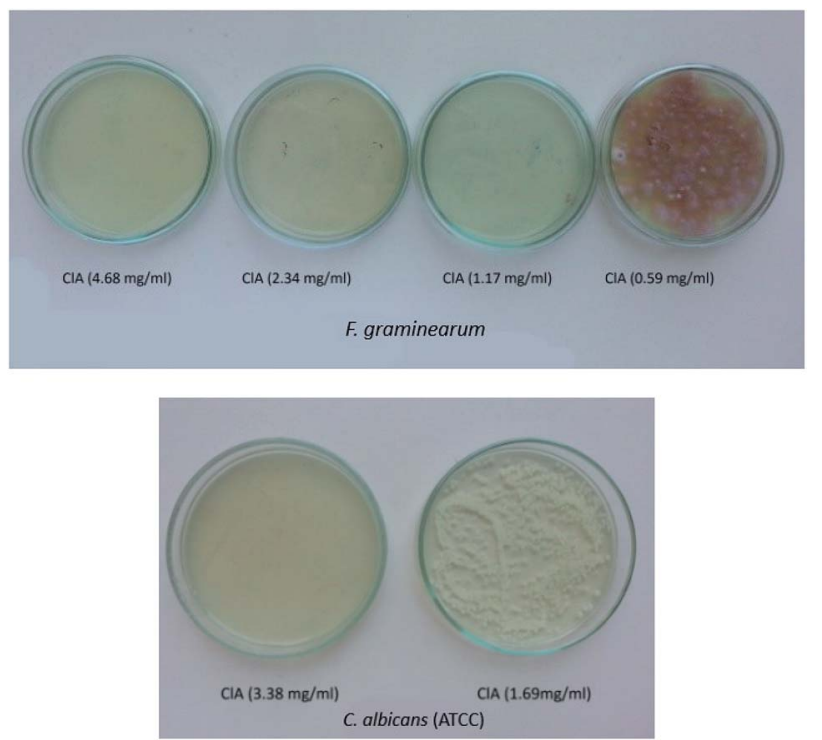

Fig. 2 Antifungal activity of protic ionic liquid 1-ammonium-2-propanol chloroacetate $(\mathrm{ClA})$ on $F$. graminearum $(\mathrm{A})$ and $C$. albicans ATCC (B).

of the ESI, $\uparrow$ the antifungal activity of nine synthesised ionic liquids is presented for each fungal strain separately.

Described toxicity tests were performed to investigate the influence of different anions on the PILs antimicrobial activity. According to these results, all PILs included in the study showed antimicrobial properties, while the variation in the antimicrobial activity among the PILs depends on anion component. Protic ionic liquids containing $\mathrm{ClA}, 3$-ClP and 4-ClB anions showed high antifungal and antibacterial activity, even at the lowest PILs concentration. The weakest antimicrobial activity showed ionic liquids with Man and TFA anions.

For the studied PILs, the antimicrobial activity dependent on the alkyl chain length, showing maximal activity with anions containing 3 and 4 carbon atoms, respectively. Although hydrophobicity is an essential feature for antimicrobial agent membrane interactions, as it governs the extent to which the agent can partition into lipid double layer, the results revealed that the PILs show better antimicrobial activities if the longer alkyl chain is presented but in the same time contain chlorinated terminal $\mathrm{C}$ atom. However, to conjugate with biomolecules and cell membranes, studied PILs showed higher activity if the terminal $\mathrm{C}$ atom is monohalogenated (as in the case of ClA) compared to TClA and TFA, since the monohalogenated derivatives possess higher affinity to interact with the cell membrane.

It was reported that increase of the anion chain length increases the lipophilic character of compounds, while their surface tension decreases. ${ }^{33,34}$ Surface tension is a measure of the cohesion of liquids, depending therefore on the liquid structure and orientation. It is well established that, for many ILs, both the cation and the anion occupy the same plane at the liquid-gas interface, typically the cations and/or anions aliphatic moieties projecting towards the interface forming a top layer while the cations polar head groups and those of the anions form the second layer. ${ }^{35}$ While the increase of the cation aliphatic alkyl chain size, from ethyl up to octyl, leads to a surface tension 

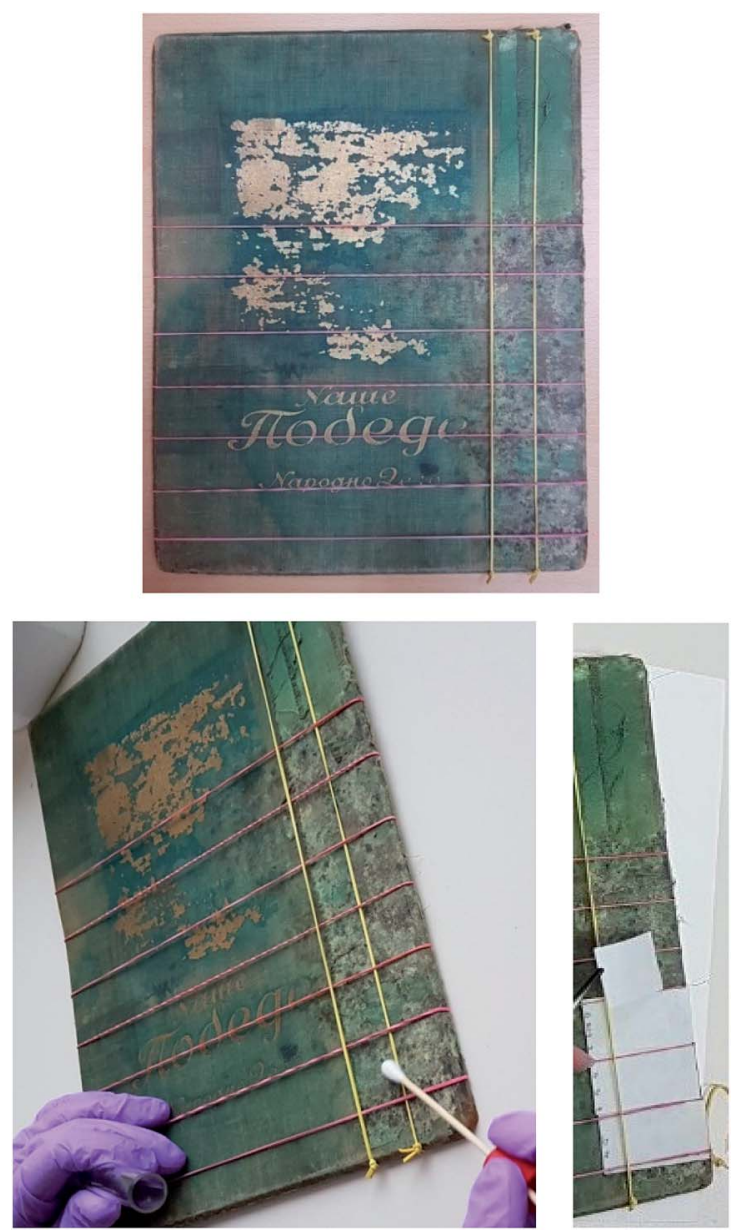

Fig. 3 Procedure of book cover cleaning.

decrease, further increase of the alkyl chain size induces a trend change, with the surface tension increasing with the increase of the alkyl chain size. ${ }^{36}$ Increased lipophilicity would be expected to increase the affinity for the cell membrane, thereby allowing a compound to penetrate more efficiently into the cell membrane, altering its nature and more effectively inhibiting bacterial and fungal growth. The optimal biological effect at a specific chain length can be attributed to the combination of several physicochemical parameters: hydrophobicity, adsorption, critical micelle concentration, effectiveness of adsorption, minimum surface area, maximum surface excess, aqueous solubility, and transport in the test medium, with the solubility being the limiting step for the transport. ${ }^{37-39}$

Introduction of the functional groups containing one chlorine atom in the anion structure leads to a significant increase in the antimicrobial activity. The best antifungal and antibacterial activity thus showed ionic liquids with ClA, 3-ClP and 4ClB anions which are illustrated in Fig. 2.

Then, the most effective PILs were chosen to be tested as alternative solvents instead of widely used thymol as the fungicide during the paper cleaning. For that purpose, five PILs with functional groups containing one chlorine atom in the anion structure (ClA, 3-ClP, 4-ClB), and two other ionic liquids that have simple and easily available anions (Ac and For) were selected. The protic ionic liquids were dissolved in sterile deionized water in the concentration range that follows their minimal inhibitory and minimal fungicide concentrations. Prepared paper stripes with ionic liquids were placed on the surface of the prepared book cover (Fig. 3) one by one, and were changed with another one every $24 \mathrm{~h}$ for the next seven days.

Due to the fact that application of the ionic liquids should not leave any structural weakening on paper artefact surface, once the treatment was completed, the effect of the ionic liquids was visible to the human eye. Paper impregnated with solutions of the ionic liquids Ac, For, 4-ClB, 3-ClP and ClA was not affected in terms of print, odour and texture - no textural changes were noticed in the paper.

Portable Digital Microscope (Levenhuk DTX 500 Mobi) was used to follow the changes during the treatment, and the results are showed in Fig. 4. As it can be seen from the Fig. 4, after the treatment microbial colonies were not detected and obtained results are in the accordance with the control one.

\section{Classification of PILs}

Chemometric analysis and classification of the studied PILs was done applying HCA and SRD analyses using the MIC data of the

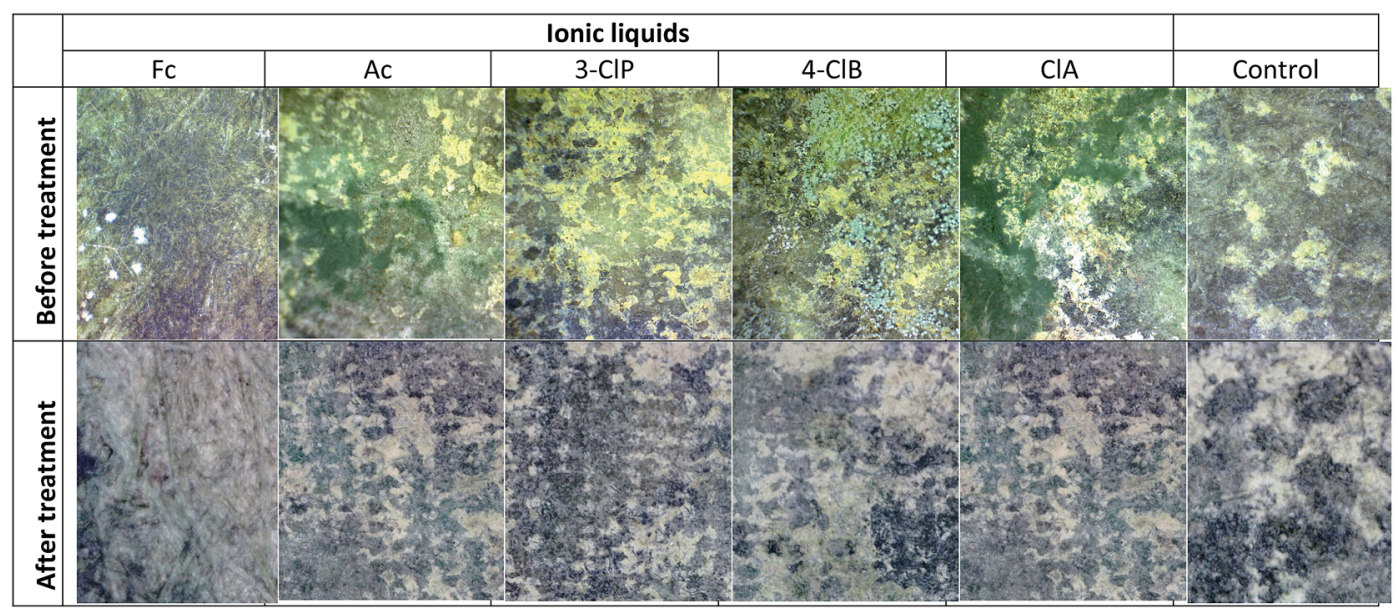

Fig. 4 Sample of paper artefact before and after treatment with selected PILs. 
PILs for Trichoderma sp., Cladosporium sp., Penicillium sp. ${ }^{(1-3)} P$. citrinum, Aspergillus sp. ${ }^{(1,2)}$, A. flavus, F. graminearum, E. faecalis $^{(19433)}$ and $K$. rhizophila ${ }^{(9341)}$. The dendrogram, given in Fig. 5, indicates two main clusters. The first one contains TClA, TFA, Man and Ac, while the second one includes 3-ClP, ClP, Lac, 4ClB and For. Generally, the studied PILs have been split, so the second cluster contains the ILs with the highest antimicrobial activity. The ionic liquids placed in the first cluster have weaker antimicrobial activity than the PILs in the second one. According to the dendrogram, 3-ClP and ClA express the most similar antimicrobial activity.

The SRD analysis was conducted by two reference rankings: minimum row values and average row values of the MIC. The ranking based on minimum row values marked the ClA as an ionic liquid with the highest antimicrobial activity, since it is the closest to the reference ranking. The Ac is placed at a maximum distance from the reference, and it expresses the weakest antimicrobial activity. If the dendrogram (Fig. 5), and SRD graph (Fig. 6A), are compared, it can be seen that SRD analysis similarly divides the PILs as the HCA. The PILs placed in the second cluster of the dendrogram (ClA, 4-ClB, 3-ClP, For and Lac) are the closest to the reference ranking. Indeed, these PILs have higher antimicrobial activity than the PILs placed in the first cluster.

If the average row values of MIC are used as the reference ranking, the obtained ranks of the PILs are certainly different than the ranks obtained by using minimum row values of MIC (Fig. 6B). The PILs with average MIC values (which are significantly higher than detected minimum MICs) are now put closer to the reference ranking. In this case, the PILs with the strongest antimicrobial activity is placed far from the average and in this way their separation is successfully achieved. As an ionic liquid with the strongest antimicrobial activity, the ClA is placed at a maximum distance from the reference. In Fig. $6 \mathrm{~B}$, it is also observable that the PILs from the first cluster in the dendrogram (Fig. 5) is the closest to the reference ranking (average) as compounds with low antimicrobial activity (relatively high MIC values). The results of the SRD analysis are in agreement with the HCA results and the experiments since the SRD split the PILs into quite similar groups which were presented in the

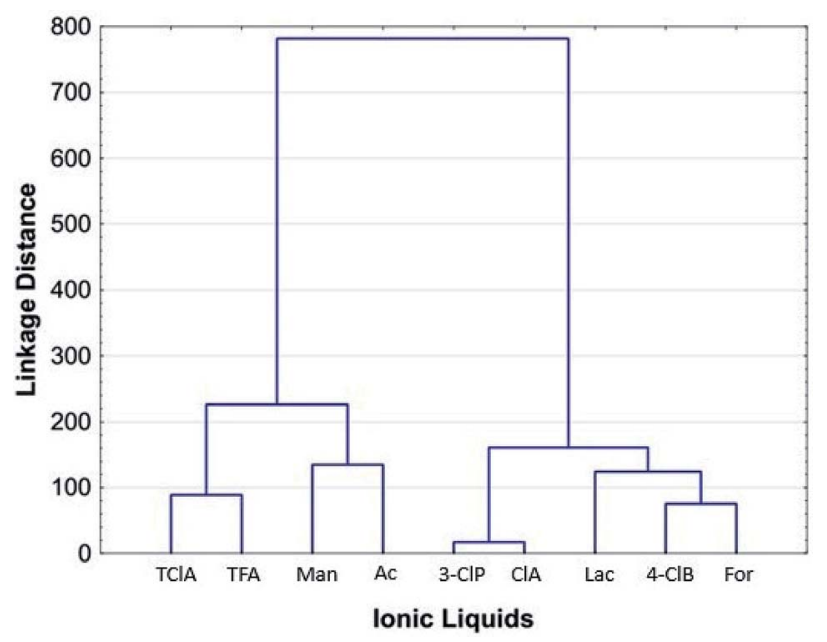

Fig. 5 The HCA dendrogram of the studied PILs based on MIC values.

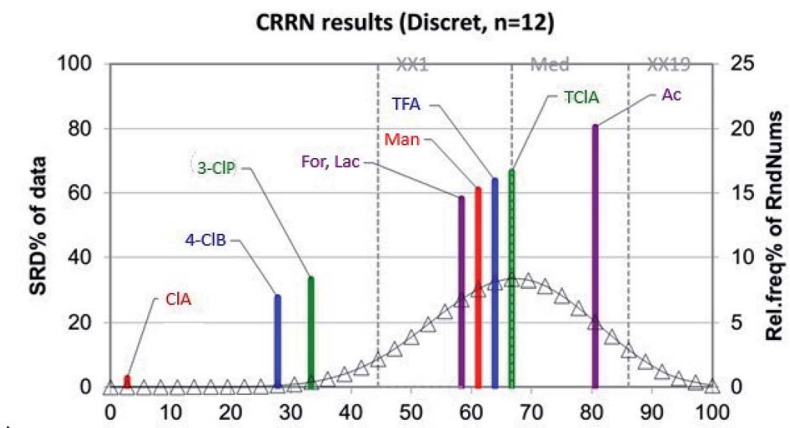

A)

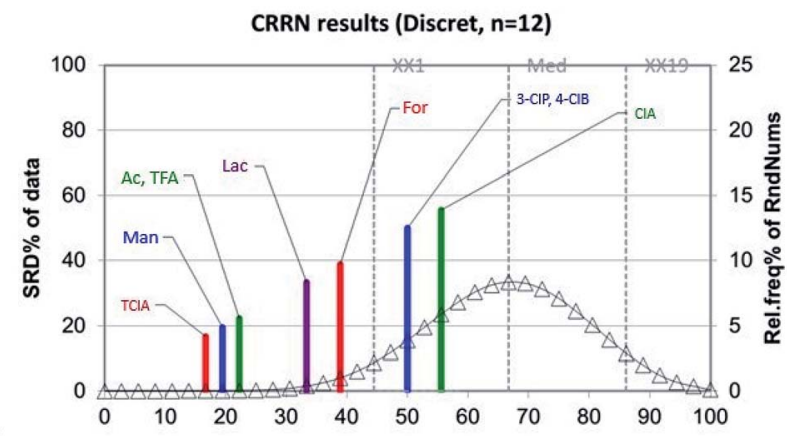

B)

Fig. 6 The graphical representation of the results of the SRD analysis of the analyzed PILs based on minimum row values (A) and average row values of MIC (B); the statistical characteristics of the theoretical distribution functions are: first icosaile $(5 \%), X X 1=32$; first quartile, $Q_{1}$ $=42$; median, Med $=48$; last quartile, $Q_{3}=54$; last icosaile $(95 \%)$, $X X 19=62$

dendrogram as clusters, despite the fact that these two methods have entirely different mathematical approaches. The ClA is distinguished as an ionic liquid with the highest antimicrobial potential toward all analysed microorganisms, followed by 3ClP and 4-ClB.

\section{Conclusions}

In this paper antimicrobial activity of newly synthesized protic ionic liquids has been investigated using ten fungi strains: Trichoderma sp., Cladosporium sp., Penicillium $\mathrm{sp}^{(1-3)}$, P. citrinum, Aspergillus sp. ${ }^{(1,2)}$, A. flavus, $F$. graminearum, eight ATCC bacterial strains: B. subtilis ${ }^{(6633)}$, S. aureus $^{(6538)}$, E. faecalis $^{(19433)}$, K. rhizophila ${ }^{(9341)}$, E. coli ${ }^{(11229)}$, S. enteritidis $^{(13076)}$, P. mirabilis $^{(12453)}$, P. aeruginosa ${ }^{(15692)}$ and two Candida strains: $C$. albicans $^{(\mathrm{ATCC} 10231)}$ and C. albicans $^{(\mathrm{L})}$. The results indicated that all nine ionic liquids showed antimicrobial activity. The HCA and SRD analyses showed the separation of PILs into two main groups, based on their antimicrobial potential toward the analysed microorganisms. The SRD analysis distinguished the ClA as an ionic liquid with the highest antimicrobial potential, followed by 4-ClB and 3-ClP. The findings obtained by HCA and SRD are comparable and quite similar, despite the fact that these two chemometric methods have quite different basics. Five selected PILs were successfully tested as the green alternatives to conventionally used thymol for paper cleaning and conservation. 


\section{Conflicts of interest}

There are no conflicts to declare.

\section{Acknowledgements}

This work was financially supported by the Ministry of Education, Science and Technological Development of Republic of Serbia under project contract ON172012.

\section{References}

1 M. Cernic Letnar and J. Vodopivec, Restaurator, 1997, 18, 73.

2 H. Szczepanowska and A. R. Cavaliere, Conserving Our Cultural Heritage: The Role of Fungi in Biodeterioration, in Bioaerosols - Fungi, Bacteria, Mycotoxins in Indoor and Outdoor Environments and Human Health, ed. E. Johanning, P. Morey and P. Auger, Fungal Research Group, Albany, 2012, pp. 293-309.

3 G. Cavallaro, S. Milioto, F. Parisi and G. Lazzara, ACS Appl. Mater. Interfaces, 2018, 10, 27355.

4 A. Sierra-Fernandez, L. S. Gomez-Villalba, M. E. Rabanal, R. Forta and L. Csókad, RSC Adv., 2016, 6, 51583.

5 G. Cavallaro, G. Lazzara, S. Milioto and F. Parisi, Chem. Rec., 2018, 18, 940.

6 S. A. Buchanan, Pap. Conserv., 1987, 11, 69.

7 W. Sobucki and B. Drewniewska-Idziak, Restaurator, 2003, 24, 189.

8 M. C. Area and H. Cheradame, BioResources, 2011, 6, 5307.

9 N. Gurnagul, R. C. Howard, X. Zou, T. Uesaka and D. H. Page, J. Pulp Pap. Sci., 1993, 19, J160.

10 A. Johansson and H. Lennholm, Appl. Surf. Sci., 2000, 161, 163.

$11 \mathrm{~W}$. A. Johnson, The practical guide to book repair and conservation, Thames and Hudson, London, 1992.

12 L. H. Isbell, The effects of thymol on paper, pigments, and media, Abbey Newsletter, 1997, 21, 39.

13 M. McCann, Artist Beware, Guilford, CT, The Lyons Press, 1992, p. 549.

14 S. Stolte and P. Stepnowski, Curr. Org. Chem., 2011, 12, 1871. 15 R. D. Rogers and K. R. Seddon, Ionic Liquids as Green Solvents: Progress and Prospects, ACS Symposium Series, Washington D.C., American Chemistry Society, 2003.

16 A. Koziróg and A. Wysocka-Robak, Application of Ionic Liquids in Paper Properties and Preservation, in Progress and Developments in Ionic Liquids, ed. Scott H., InTechOpen, New York, 2017.

17 A. Koziróg, A. Wysocka-Robak and K. Przybysz, Fibres Text. East. Eur., 2015, 23, 134.

18 K. Przybysz, E. Drzewińska, A. Stanisławska, A. WysockaRobak, A. Cieniecka-Rosłonkiewicz, J. Foksowicz-Flaczyk and J. Pernak, Ind. Eng. Chem. Res., 2005, 44, 4599.
19 K. S. Egorova, E. G. Gordeev and V. P. Ananikov, Chem. Rev., 2017, 117, 7132.

20 D. Han and K. H. Row, Molecules, 2010, 15, 2405.

21 A. Kokorin, Ionic Liquids: Applications and Perspectives, InTechOpen, New York, 2011.

22 I. Cota, R. Gonzalez-Olmos, M. Iglesias and F. Medina, J. Phys. Chem. B, 2007, 111, 12468.

23 Clinical and Laboratory Standards Institute, Methods for Dilution Antimicrobial Susceptibility Tests for Bacteria That Grow Aerobically; Approved Standard-Ninth Edition, CLSI document M07-A9, Wayne, PA, 2012.

24 N. Spremo, K. Tešanović, M. Rakić, L. J. Janjušević, M. Ignjatov, D. Bijelić and M. Karaman, Proc. Nat. Sci. Matica Srp., 2017, 133, 231.

25 M. Ž. Karadžić, D. M. Lončar, G. Benedeković, I. Kovačević, V. Popsavin, S. Z. Kovačević, L. R. Jevrić and S. O. Podunavac-Kuzmanović, Eur. J. Pharm. Sci., 2017, 105, 99.

26 S. Z. Kovačević, L. R. Jevrić, S. O. Podunavac-Kuzmanović, N. D. Kalajdžija and E. S. Lončar, Acta Chim. Slov., 2013, 60, 420.

27 J. N. Miller and J. C. Miller, Statistics and chemometrics for analytical chemistry, Pearson Education Limited, Harlow, UK, 6th edn, 2010.

28 STATISTICA (data analysis software system), version 10, StatSoft Inc, 2011. http://www.statsoft.com.

29 K. Héberger and K. J. Kollár-Hunek, J. Chemom., 2011, 25, 151.

30 K. Kollár-Hunek and K. Héberger, Chemom. Intell. Lab. Syst., 2013, 127, 139.

31 M. Vračko, N. Minovski and K. Héberger, Acta Chim. Slov., 2010, 57, 586.

32 S. Z. Kovačević, S. O. Podunavac-Kuzmanović, L. R. Jevrić, E. A. Djurendić, J. J. Ajduković, S. B. Gadžurić and M. B. Vraně̌, J. Iran. Chem. Soc., 2016, 13, 499.

33 E. Freese, C. W. Sheu and E. Galliers, Nature, 1973, 241, 321. 34 M. Dymicky, M. Bencivengo, R. L. Buchanan and J. L. Smith, Appl. Environ. Microbiol., 1987, 53, 110.

35 C. S. Santos and S. Baldelli, Chem. Soc. Rev., 2010, 39, 2136. 36 H. F. Almeida, M. G. Freire, A. M. Fernandes, J. A. Lopes da Silva, P. Morgado, K. Shimizu, E. J. Filipe, J. N. Lopes, L. M. Santos and J. A. Coutinho, Langmuir, 2014, 30, 6408.

37 C. Morán, P. Clapés, F. Comelles, T. García, L. Pérez, P. Vinardell, M. Mitjans and M. R. Infante, Langmuir, 2001, 17, 5071.

38 T. J. Franklin and G. A. Snow, Biochemistry of Antimicrobial Action, Chapman and Hall, London, UK, 1985.

39 M. M. A. El-Sukkary, N. O. Shaker, A. Dina, S. Ismail, M. Ahmed, M. F. Zaki and A. I. Awad, Egypt. J. Pet., 2012, 21, 37 . 